\title{
Stability analysis of pigeon pea genotypes by deployment of AMMI model under rainfed environment
}

\author{
Jogendra Singh*, Amit Kumar' ${ }^{1}$,Abdul Fiyaz $\mathbf{R}^{1}$ and Muneendra Kumar Singh ${ }^{2}$ \\ ICAR Research Complex for NEH Region, \\ Manipur Centre, Lamphelpat, Imphal-795 004, Manipur, India. \\ Received: 21-05-2016 \\ Accepted: 14-09-2016
}

DOI: $10.18805 / 1 \mathrm{r} . \mathrm{v} 0 \mathrm{i0} 0.7851$

\begin{abstract}
Twenty one genotypes of pigeon pea were evaluated in a randomized complete block design during the kharif season of 2007-08, 2008-09 and 2009-10 based upon number of primary branches per plant, pod length, number of grains per pod, 100 -seed weight and seed yield per plant. The stability was studied by deploying AMMI (additive main effects and multiplicative interaction) model. The significant differences among the years were observed and measured more than $50 \%$ of the treatment sum of squares. First principal component axis (PCA1) of the interaction captured more than $60 \%$ of the interaction sum of squares for almost all the traits studied. The mean seed yield per plant was found highest (39.15 g) and at par similar in all the three years. Nine stable and high yielding genotypes viz., PUSA 2003-1; CORG-2001-5; WREG- 28; PANT-A-286; H-94-6; GT 101; ICPL-99004; ICPL-85010 and UPAS-120 exhibited stable performance under the rainfed environmental conditions for more than one traits studied and also under more than one year.
\end{abstract}

Key words: AMMI model, Pigeon pea, Rainfed, Stability.

\section{INTRODUCTION}

Pigeon pea [Cajanus cajan (L.) Millspaugh] occupies an important place under rain-fed agriculture among sub-tropical grain legumes (Saxena et al. 2010). It can be grown under wide climatic conditions and also can be intercropped with virtually any crop with no allelopathic effect on the main crop (Baskaran and Muthiah, 2005). Globally, pigeon pea is cultivated on 4.86 million hectares area with production of 4.10 million tones and productivity of $844 \mathrm{~kg}$ /ha (FAOSTAT, 2011). In India, after chick pea, pigeon pea is the second most important pulse crop and it contributes more than $85 \%$ of the world production and consumption (Danekar et al. 2014). Pigeon pea is a rich source of vegetarian protein $(22 \%)$ and plentiful sulphur containing amino acid. It is consumed in the form of split pulse as 'dal'. Besides this, in tribal areas of various states, the consumption of pigeon pea as green vegetable is very common (Saxena et al. 2010). Moreover, it plays a critical role in maintaining the soil fertility by fixing the atmospheric nitrogen and by falling down the dry leaves of pigeon pea on the soil surface. Pigeon pea is affected by various abiotic stresses during its life cycle such as moisture, temperature, photoperiod and mineral stresses. Among stresses, moisture stress is common because pigeon pea is grown as a rain-fed crop (Chaudhary et al. 2011). There is higher possibility that a genotype performing well under non-stress conditions will also perform well under moisture stress even if the relative yield reduction is large. An ideal genotype for moisture stress environment must combine reasonably high yield potential with stress-specific plant characters that buffer yield against severe moisture stress (Blum, 1983). The phenotype of an individual plant is determined by both its genotype and environment. These two effects are not always additive because of the presence of genotype and environment interaction (GEI), measured as inconsistent performance of a genotype across environments. The $\mathrm{G} x \mathrm{E}$ interaction is an important aspect of plant breeding (Freeman, 1985). An ideal or stable variety should have high mean yield with low degree of GEI, when grown over varied environment. Several methods have been put forwarded to analyze GEI and phenotypic stability. These methods can be classified into two major groups, viz. univariate and multivariate stability statistics. Among multivariate methods, the additive main effects and the multiplicative interaction analysis (AMMI) model is widely used in GEI studies for different crops (Singh et al. 2000 and Crossa et al. 1990) to separate the additive portion from interaction by way of an analysis of variance. This model discriminates clearly between main and interaction effects and usually desirable in order to make reliable yield estimations (Gauch, 1992). AMMI biplot analysis is considered to be an effective tool to detect the GE interaction patterns graphically. The AMMI model describes the GE interaction in more than one dimension and it offers better opportunities for interpreting GE

\footnotetext{
*Corresponding author's e-mail: jogendrasail@yahoo.co.in

${ }^{1}$ ICAR-Indian Institute of Wheat and Barley Research, Karnal- 132 001, Haryana, India.

${ }^{2}$ ICRISAT, Patancheru, Hyderabad-502 324, Telangana, India.
} 
interaction than analysis of variance (ANOVA) and regression of the mean (Vargas et al., 2001). In AMMI model, firstly, the main additive effects of genotype and environment are considered by variance analysis and then are analyzed by principal characteristics of remain value from variance analysis model (Gauch and Zobel, 1997). In fact, AMMI model follows three basic principles: i) it is an appropriate model for primary analysis of performance tests. ii) It explains the effect of genotype $\mathrm{x}$ environment and iii) performance estimate is done by more accuracy. In the above perspectives, present study was therefore, aimed to estimate the stability analysis and suitability along with adaptability of 21 pigeon pea genotypes evaluated during three years in foot hills of Manipur by using AMMI analysis.

\section{MATERIALS AND METHODS}

The experimental material comprised of 21 genotypes of pigeon pea collected from three locations namely, G.B. Pant University of Agriculture and Technology, Pantnagar, International Crops Research Institute for the Semi-Arid Tropics, Hyderabad and Indian Institute of Pulses Research, Kanpur, India. The genotypes were evaluated in a randomized complete block design with three replications during kharif 2007-08, 2008-09 and 2009-10 under rainfed field conditions at Langol farm, Imphal, Manipur. $\left(42.54^{\circ} \mathrm{N}\right.$, 93. $5^{\circ} \mathrm{E}$ and $774 \mathrm{~m}$ above sea level.). The soil of experimental field was sandy loam with $\mathrm{pH}$ 5.5. Each plot consisted of two rows of $4 \mathrm{~m}$ long. The spacing between row to row and plant to plant was kept $60 \mathrm{~cm}$ and $20 \mathrm{~cm}$ respectively. Standard agronomic practices were followed to raise the normal crop in each year. The observations were recorded on five randomly selected plants from each genotype mainly for yield component traits such as; number of primary branches/plant, pod length $(\mathrm{cm})$, number of grains/pod, 100seed weight $(\mathrm{g})$ and seed yield/plant $(\mathrm{g})$. The stringent phenotyping were imposed for stability analysis over the years. The data were subjected for analysis of genotypeenvironment interaction with AMMI model by considering the first two principal components in SAS 9.2 and IRRISAT 4.3 software (IRRI, 2002). AMMI is powerful tool for analysis of $\mathrm{G} x \mathrm{E}$ interactions that utilizes standard analysis of variance and principal component analysis (PCA) to identify the patterns in the data (Gauch, 1992, 2006, Yan and Rajcan (2002).

\section{RESULTS AND DISCUSSION}

The AMMI analysis of variance of 21 pigeon pea genotypes evaluated for 3 consecutive years (2007-2010) is presented in Table 1. The partitioning of total sum of square revealed that years effects were predominant followed by $\mathrm{G}$ $\mathrm{x}$ E interaction and genotype effect. Generally, AMMI model showed significant differences for the years and that accounted more than $50 \%$ of the total sum of square (SS) for all the traits under study excepting for seed yield/plant $(0.8 \%)$, 100 - seed weight (23.3\%) and number of grains/pod (27.4\%).

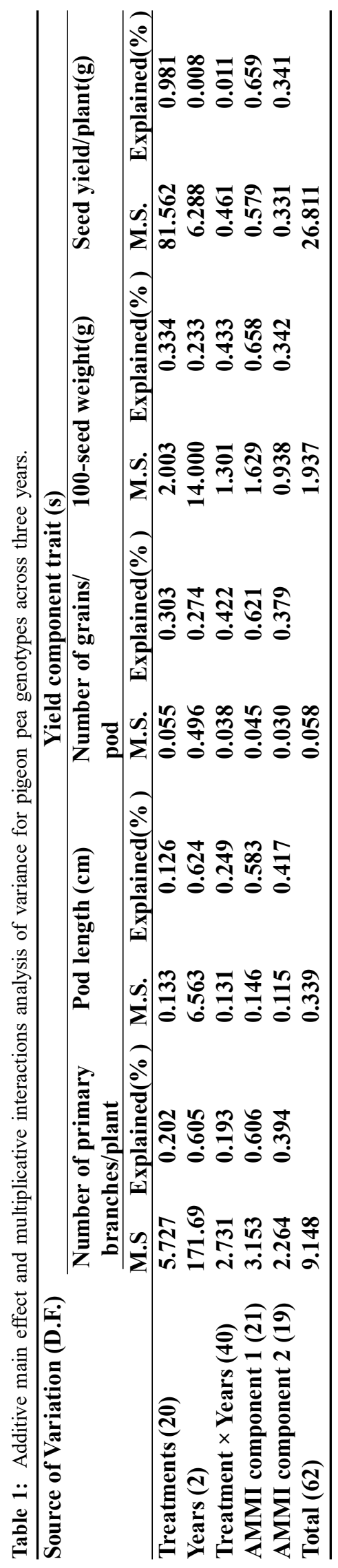


A large sum of squares for the years indicated that the effect of the years were diverse and variable in nature with large differences among years, causing most of the variation for yield and its component traits. The contribution of $\mathrm{G} \times \mathrm{E}$ interaction to the TSS was found to be $30.2 \%$ excepting the seed yield/plant (1.1\%) which was larger than those contributed by genotypes alone (20.9\%). However, highest variation of the TSS was contributed by genotype (98.1\%) for seed yield/plant than other traits.

The ANOVA for primary branches/plant explained $60.5 \%$ variation due to differences in environment while genotypes and G x E interaction captured $20.2 \%$ and $19.3 \%$ respectively. Similarly, ANOVA for the pod length revealed $62.4 \%$ proportion of variance due to differential response of environments followed by G x E interactions (24.9\%) and due to genotypic effects alone $(12.6 \%)$. In case of pod length, magnitude of $\mathrm{G} \times \mathrm{E}$ was $\sim 2$ times higher than the genotype effect across the years (Table 1). Our results are also supported with findings of Rashidi et al. (2013). However, Tolessa et al. (2013) reported that G x E interaction effect was almost four times greater than the genotype effect. Similar to this the ANOVA for number of grains per pod showed that $\mathrm{G} \times \mathrm{E}$ interaction accounted the largest (42.2\%) percentage of total sum of squares followed by genotype effect (30.3\%) and environment (27.4\%). Similarly, ANOVA for 100-seed weight explained that the largest portion of variation was captured by $\mathrm{G} \times \mathrm{E}$ interaction (43.3\%), followed by genotypic response $(33.4 \%)$ and due to environment (23.3\%). Eventually, it indicated that both of the traits contributed much of the variance, owing to $\mathrm{G} \times \mathrm{E}$ interaction and genotypes.

AMMI analysis of variance for seed yield/plant showed that major portion of variance of the TSS was captured by genotypic effect $(98.1 \%)$ while only a small portion of the total sum of squares was attributed by $\mathrm{G} \times \mathrm{E}$ interaction $(1.1 \%)$ and environment $(0.08 \%)$. A larger SS for genotype effect indicated that the genotypes were varied with large differences among the genotypic means. The small proportion of SS for environment showed that the difference among the environmental means was not very high. The magnitude of sum of squares due to $G \times E$ was 89 times smaller than genotype, indicating that the differences in the response of the genotypes across years were not substantial. These findings are also in agreement with Mukherjee et al., (2013).

The AMMI analysis showed presence of $\mathrm{G} \times \mathrm{E}$ interactions and this has been partitioned among the first and second IPCA (Interaction Principal Components Axes). The results from AMMI analysis (Table 1) revealed that the first IPCA captured more than $60 \%$ of the interaction sum of squares for all the traits excepting for the pod length. However, second IPCA explained more than $25 \%$ of the GEI sum of squares. Furthermore, IPCA 1 and IPCA 2 had higher

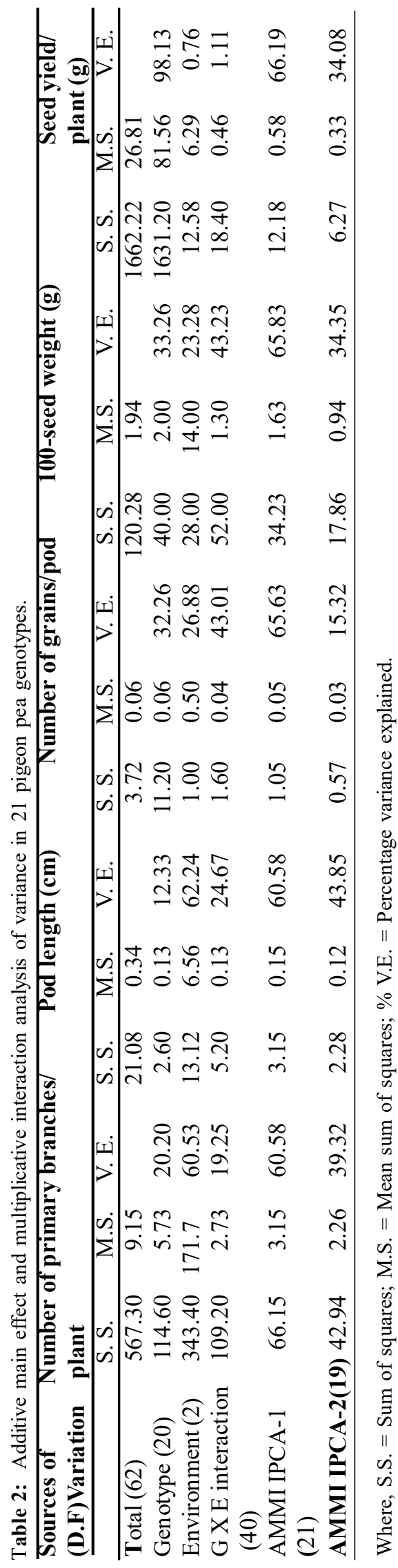



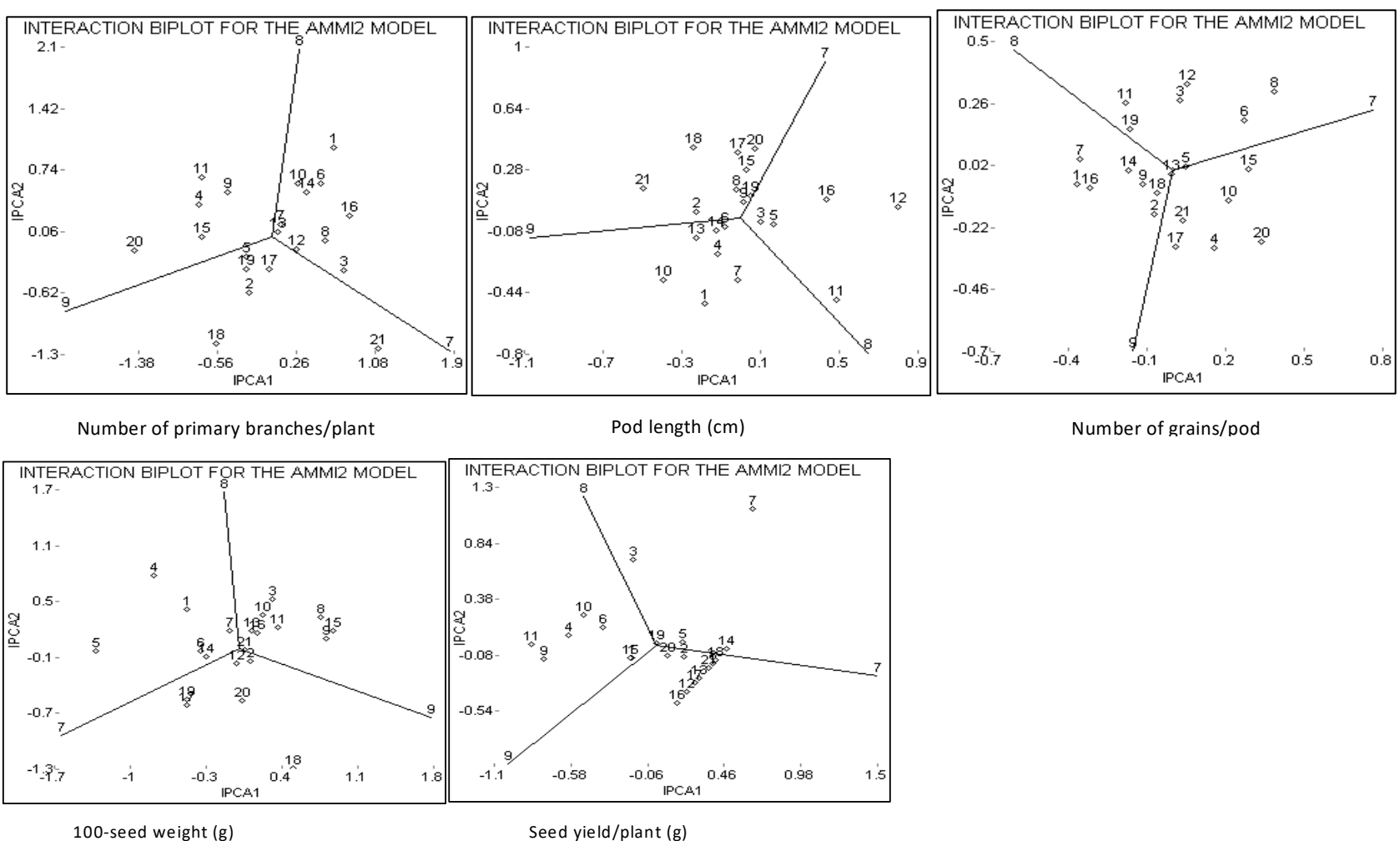

Fig 1: AMMI 2 biplot of 21 pigeon pea genotypes using genotypes and environment scores.

sum of squares than genotype except seed yield/plant. The mean squares for IPCA 1 and IPCA 2 were significant $(\mathrm{P}=$ 0.01 ) and cumulatively contributed to more than $90 \%$ of the total GEI. Thus prediction assessment indicated that AMMI with two interaction principal component axes was the best predictive model (Zobel et al., 1988).

IPCAs crossover and non-cross over interaction : Interaction principal component axes (IPCAs) scores of genotypes and environments exhibited positive and negative values (Table 2). It is obvious that a genotype with larger positive IPCA score in some environments must have larger negative interaction in some other environments. Thus, these scores showed varying genotype response (Yan and Hunt, 2001; Mohammadi et al., 2007), which was the major source of variation for any crossover (qualitative) interaction. This inconsistent genotype response is referred to as crossover GE interaction for convenience. In contrary, scores with the same sign or near zero represent a non-crossover (quantitative) GE interaction or a proportionate genotype response as reported by Mohammadi and Amri (2008); Farshadfar, (2008).

AMMI stability value (ASV): AMMI stability values (ASV) were calculated in order to quantify and rank the genotypes according to their yield stability. This measure was proposed by Purchase et al. (2000). In fact, ASV is the distance from zero in a two dimensional scatter gram of IPCA1 (interaction principal component analysis axis 1) scores against IPCA2 scores. In ASV method, a genotype with least ASV score will be most stable. According to Bajpai and Prabhakaran (2000), genotypes should be ranked based on the stability index (SI) which brings both mean value as well as AMMI stability value on same platform and thus could be more fruitful as compared to considering alone AMMI stability values. We presented herein stable genotypes for each trait separately for year 2007, 2008 and 2009.

Number of primary branches/plant: For mean performance across different years ICPL-99004, ICPL-88034 and ICPL85010 were found to be superior. As far as AMMI stability value is concerned, AL-1491 and Phule T-8020 were promising. ICPL-99004 and ICPL-85010 were also superior when stability index was estimated (Table 3). In the Figure 1 , the best genotype with respect to year 2007 was genotype UPAS-120 (21) and TT-302 (3). Genotype Pusa-2003-1 (1), Pant A-286 (10) and WREG-28 (6) were best for year 2008 whereas genotypes ICPL-85010 (20) and GT-101 (15) were best for year 2009.

Pod length (cm) : For mean performance across different years ICPL-98015, ICPL-88034 and UPAS-120 were found to be superior. For AMMI stability value H-82-1, WREG28, TT-302 and ICPL-99004 were high performing genotypes. Among these H-82-1 and ICPL-98015 had also shown low score as far as stability index is concerned. The best genotype with respect to year 2007 was genotype ICPL85010 (20) and ICPL-98015 (17). The genotype H-94-6 (11) 
Table 3 Continue.

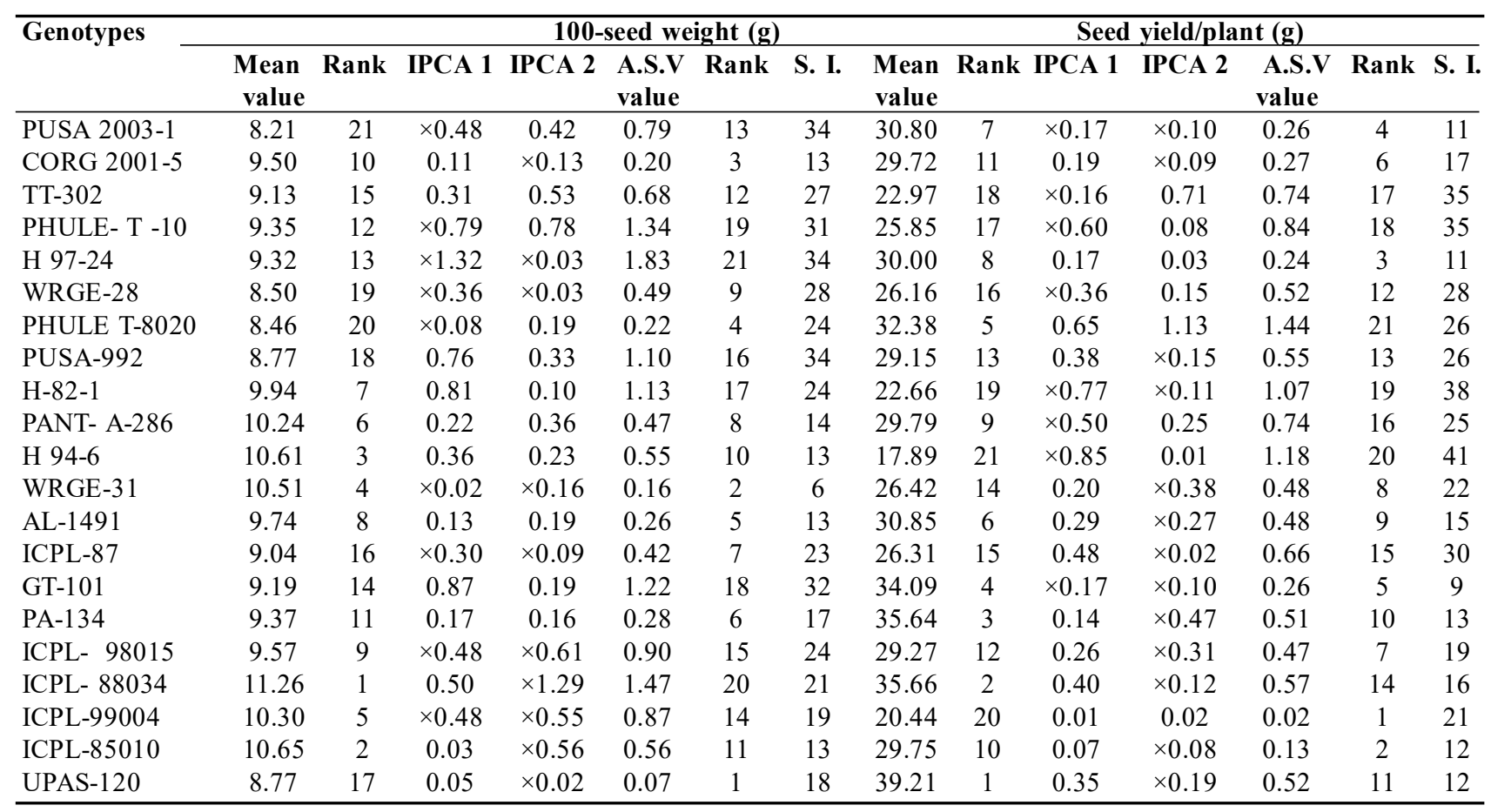

was best for year 2008 whereas genotypes UPAS-120 (21) and CORG-2001-5 (2) were best for year 2009. (Figure 1) Number of grains/pod : Genotypes viz., GT-101, UPAS120, ICPL-98015 and ICPL-87 were found to be superior as far as mean value is concerned. For AMMI stability value AL-1491, H-97-24 and ICPL-88034 were high performing genotypes. Among these UPAS-120 and ICPL-87 had also shown low score as far as stability index is concerned. Genotype viz., WREG-28 (6) and Pusa-992 (8) were best performing genotype with respect to year 2007. Genotype H-94-6 (11) and ICPL-99004 (19) were best for year 2008 whereas genotypes UPAS-120 (21) and CORG-2001-5 (2) were best for year 2009. (Figure 1)

100-seed weight (g) : For this trait, ICPL-88034, H-94-6 and WREG-31 had high seed weight throughout different years. UPAS-120 followed by WRGE-31 and Phule T-8020 had shown stable behaviour as far as AMMI stability value is concerned. WREG-31, Pant A-286 and H-94-6 had also shown low score for stability index. Genotypes viz., ICPL99004 (19) and Pusa-2003-1 (1) were best performing genotypes with respect to year 2007. Genotypes TT-302 (3) and Pant A-286 (10) were best for year 2008 whereas genotypes GT-101 (15) and H-82-1(9) were best for year 2009. (Figure 1)

Seed yield/plant (g) : The average seed yield per plant for the year 2007, 2008 and 2009 were 28.18, 29.15 and 29.10 g respectively. UPAS-120, ICPL-88034, PA-134 and GT101 had shown more seed yield per plant throughout different years. ICPL-99004 followed by ICPL-85010 and H-97-24 had shown less scores for AMMI stability value (Table 3 ). GT-101, H-97-24, UPAS-120 and ICPL-85010 were more stable with high mean yield as shown by stability index. The AMMI 1 biplot with the main effects plotted against the IPCA 1 scores explained $65.9 \%$ of the G x E interaction SS. The average seed yield/plant for the 21 genotypes in each year measured was $28.18 \mathrm{~g}$ in 2007, 29.15 g in 2008 and $29.10 \mathrm{~g}$ in 2009. (Figure 1)

Based upon all the five traits studied and performance over the three years, we have selected some higher yielding and stable genotypes for rainfed environmental conditions. The ICPL 85010 (based upon pod length in the year 2007 and number of primary branches per plant in the year 2009); WREG-28 (no. of grains/pod in year 2007 and primary branches in year 2008); PUSA 2003-1 (hundred seed weight in year 2007 and primary branches in year 2008); PANT A-286 (primary branches and hundred seed weight in the year 2008); H-94-6 (pod length and number of grains per pod in the year 2008); ICPL 99004 (hundred seed weight in the year 2007 and number of grains per pod in the year 2008); UPAS-120 (primary branches per plant in the year 2007 and pod length as well as number of grains per pod in the year 2009); GT 101 (primary branches and hundred seed weight in the year 2009); and CORG-20015 were best stable genotypes as based upon pod length as well as number of grains per pod in the year 2009 . 
The results of this investigation proved that IPCC crossover and non-cross over interaction along with AMMI stability value (ASV) and stability index (SI) are suitable stability indices for discriminating stable genotypes with high mean performances. Stability index which incorporate ASV and mean performances in a single non-parametric index is most desirable for discriminating the most stable genotypes with high performance.

\section{ACKNOWLEDGMENT}

Authors are thankful to the Director, ICAR Research Complex for NEH Region, Umiam, Meghalaya and Joint Director, ICAR Research Complex for NEH Region, Manipur Centre, Imphal for providing the facilities during research work. We are also grateful to Dr. K.B. Saxena, Pigeon pea breeder, ICRISAT, Hyderabad, for providing the seeds of pigeon pea genotypes for research purpose.

\section{REFERENCES}

Bhaskaran, K. and Muthiah, A. R. (2005). Screening and inheritance pattern of sterility mosaic disease resistance in pigeonpea. Indian J. Pulses Res., 18: 124-126.

Blum, A. (1983). Breeding programmes for improving crop resistance to water stress. In: [Raper C.D. and Kramer P.J. (eds)]. Crop Reaction to Water and Temperature Stress in Humid Temperate Climates. Westview Press, Boulder Co. USA. pp. 263-274.

Bajpai, P.K. and Prabhakaran, V.T. (2000). A new procedure of simultaneous selection for high yielding and stable crop genotypes. Indian J. Genet. 60: 141-146.

Chaudhary, A.K., Sultana, R., Pratap, A., Nadarajan, N. and Jha, U.C. (2011). Breeding for abiotic stresses in pigeon pea. J. Food Leg., 24(30): 165-174.

Crossa, J., Gauch, H.G. and Zobel, R.W. (1990). Additive main effects and multiplicative interaction analysis of two international maize trials. Crop Sci., 30: 493-500.

Danekar, P., Tyagi, A., Mahto, A., Krishna, K.G., Singh, A., Raje, R. S., Gaikward, K. and Singh, N.K. (2014). Genome wide characterization of Hsp 100 family genes from pigeon pea. Indian J. Genet., 74(3): 325-334.

Farshadfar, E. (2008). Incorporation of AMMI stability value and grain yield in single non-paramrtric index (GSI) in bred wheat. Pak. J. Biol. Sci. 11(14): 1791-1796.

FAOSTAT. (2011). Available online at: http://faostat.fao.org/.

Freeman, G.H. (1985). The analysis and interpretation of interaction. J. Appl. Stat., 12:3-10.

Gauch, H. G. (1992). Statistical analysis of regional trials- AMMI analysis of factorial design. $1^{\text {st }}$ ed. Elsevier, Amsterdam, New York.

Gauch, H. G. (2006). Statistical analysis of yield trials by AMMI analysis and GGE. Crop Sci. 46:1488-1500.

Gauch, H.G. and Zobel, R.W. (1997). Identifying mega-environment and targeting genotypes. Crop Sci. 37: 311-326.

IRRI. (2002). IRRISAT 4.3 for windows. Tutorial manual. Biometrics units. International Rice Research Institute, Philippines, pp. 182 Mohammadi, R., Abdulahi, A., Haghparast, R. and Armion, M. (2007). Interpreting genotype- environment interactions for durum wheat grain yields using non-parametric methods. Euphytica. 157: 239-251.

Mohammadi, R. and Amri, M. (2008). Comparison of parametric and non-parametric methods for selecting stable and adapted durum wheat genotypes in variable environments. Euphytica. 159: 419-432.

Mukherjee, A.K., Mohapatra, N.K., Bose, L.K., Jambhulkar, N.N. and Nayak, P. (2013). Additive main effects and multiplicative interaction (AMMI) analysis of GxE interactions in rice blast pathosystem to identify stable resistant genotypes. African J. of Agri. Res. 8(44): 5492-5507.

Purchase, J. L., Hatting, H. and Vandeventer, C. S. (2000). Genotype $\times$ environment interaction of winter wheat (Triticum aestivum L.) in South Africa: Đ. Stability analysis of yield performance. S. Afr. J. Plant Soil. 17: 101-107.

Rashidi, M., Farshadfar, E. and Jowkar, M.M. (2013). AMMI analysis of phenotypic stability in chickpea genotypes over stress and non-stress environments. Intl. J. Agri. Crop Sci., 5(3): 253-260.

Saxena, K.B., Kumar, R.V. and Gowda, C.L.L. (2010). Vegetable pigeon pea - a review. J. Food Leg., 23(2): 91-98.

Singh, P.K., Kumar S. and Singh J. (2000). Stability analysis for sugarcane genotypes grown under three different conditions. Indian J. Sugarcane Techno., 15: 52-58.

Tolessa, T.T., Keneni, G., Sefera, T., Jarso, M. and Bekele, Y. (2013). Genotype x Environment interaction and performance stability for grain yield in field pea (Pisum sativum L.) genotypes. Intl. J. Plant Breed., 7(2): 116-123.

Vargas, M., Crossa, I., Eeuwijk, F. V., Sayre, K. D. and Reynolds, M. P. (2001). Interpreting treatment x environment interaction in agronomy trials. Agron. J., 93: 949-960.

Yan, W. and Hunt, L.A. (2001). Interpretation of genotype - environment interaction for winter wheat yield in Ontrio. Crop Sci., 41: 19-25 Yan, W. and Rajcan, I. (2002). Biplot Analysis of test sites and Trait relations of Soybean in Ontario. Corp Sci., 42: 11-20. Zobel, R.W., Wright, M.S. and Gauch, H.G. (1988). Statistical analysis of a yield trial. Agron J., 80: 388-393. 